\title{
A execução da política externa brasileira: um balanço dos últimos 4 anos
}

\section{SEBASTIÃO DO REGO BARROS*}

No artigo anterior, o Ministro Luiz Felipe Lampreia fez uma avaliação das principais questões da agenda internacional e indicou as políticas adotadas pelo Brasil em cada caso. Como complemento desse panorama abrangente da atuação externa do País nos últimos quatro anos, pretendo discutir a própria execução da política exterior, isto é, as maneiras pelas quais o Itamaraty buscou modernizar-se para fazer frente aos desafios da diplomacia do período e ao crescente e indispensável interesse da Sociedade brasileira em temas de política externa. O enfoque será, portanto, institucional, com destaque para o que o Itamaraty vem fazendo, de que modo e com que grau de diálogo e interação com os demais órgãos do Governo, a iniciativa privada, as organizações sociais e a população em geral.

Uma orientação geral marcou os trabalhos do Itamaraty no período de 1995 a 1998: a necessidade de uma crescente aproximação da instituição com a sociedade. Na seqüência de um processo iniciado com a redemocratização do País e em conformidade com a proposta do Governo Fernando Henrique Cardoso de valorizar a cidadania e de tornar mais transparente o Estado brasileiro, o Itamaraty procurou aprofundar o diálogo com entidades sociais, parlamentares, governos estaduais e municipais, empresários, sindicalistas, ONGs e imprensa. Partiu-se do pressuposto de que a política externa seria tanto mais instrumental ao desenvolvimento do País quanto mais aberta estivesse à discussão e ao acompanhamento da sociedade.

Este artigo divide-se em três partes. Primeiro, apresentarei os princípios que tradicionalmente informam a diplomacia brasileira e que também orientaram a política externa durante o primeiro mandato do Governo do Presidente Fernando Henrique Cardoso. Em seguida, examinarei mais detidamente o relacionamento do Ministério das Relações Exteriores com a sociedade ao longo do período, que foi marcado por um permanente esforço de intensificar o diálogo com outros setores do Governo e entidades civis e de aumentar a transparência do processo de decisão. 
Por fim, discutirei as principais transformações realizadas no Itamaraty, que se guiaram pela convicção de que a instituição precisa aperfeiçoar os serviços que presta à sociedade, por meio de ações que favoreçam mais diretamente os cidadãos brasileiros tanto no Brasil quanto no exterior.

\section{Os princípios da política externa brasileira}

A natureza da política externa é dual. Ela obedece à articulação entre o interesse nacional e as perspectivas no âmbito internacional. Trata-se, portanto, da defesa externa de anseios domésticos. Assim, a tarefa do Ministério das Relações Exteriores como executor da política externa brasileira é buscar fazer prevalecer os interesses específicos da nossa sociedade, por meio do diálogo e da cooperação com os demais países.

Este exercício requer, do Itamaraty, uma atuação em sentidos complementares. De um lado, a atuação do âmbito Interno para o Internacional: o Ministério procura "ouvir” a sociedade e traduzir seus interesses, necessidades e valores nas ações externas do País. De outro, a atuação do âmbito Internacional para o Interno: o Itamaraty avalia as perspectivas e constrangimentos externos e procura informar e orientar a sociedade.

Não basta que o Ministério procure fazer valer os interesses domésticos em meio externo; é preciso também que a sociedade conheça as oportunidades e desafios internacionais para melhor avaliar as suas opções e pontos de vista. Cabe ao Itamaraty analisar o contexto internacional - suas tendências, configurações de poder em cada questão, os obstáculos a interesses específicos - para melhor informar a sociedade, a fim de que suas escolhas sejam realistas e compatíveis com os recursos de poder e a capacidade de atuação externa do País.

O exercício da política externa deve ainda fundamentar-se em princípios que tradicionalmente caracterizam a atuação diplomática brasileira, como a prevalência do interesse público e nacional sobre o particular e privado. $\mathrm{O}$ Itamaraty procura defender objetivos nacionais, que atendam à sociedade com um todo, e a defesa do interesse particular ocorre quando em harmonia com aquele. Para que seja defendida pelo Ministério em sua atuação internacional, a reivindicação privada - o interesse específico de uma empresa, grupo, entidade ou cidadão brasileiro - deve coincidir com os interesses do País e com valores que informam a imagem do Brasil no exterior e sua atuação diplomática, como o recurso à solução pacífica de controvérsias, a defesa da não-intervenção e da autodeterminação dos povos e a ênfase na busca do desenvolvimento.

O outro princípio é o da prevalência da visão de futuro sobre o imediatismo. O Itamaraty procura atuar tendo em vista a perspectiva de longo prazo, evitando modismos, soluções circunstanciais e precipitações que desconsideram dificuldades futuras, o grau de desgaste político e a eventual perda 
de credibilidade. $\mathrm{O}$ anseio mais imediato é avaliado com base nos seus benefícios e custos no futuro, não em seus resultados mais visíveis e freqüentemente de apelo mais fácil.

A credibilidade internacional de um país depende, em grande medida, de uma atuação externa fundada no respeito a valores e princípios. A pendularidade, o recurso a decisões de impacto, as flutuações ideológicas e o oportunismo diplomático tendem a corroer a confiança junto aos demais países e a minar a credibilidade externa. Um dos patrimônios do Itamaraty e da diplomacia brasileira é o legado de uma atuação fundada em valores permanentes, que conferem um mínimo de regularidade ao comportamento externo do País e, portanto, à sua própria respeitabilidade como interlocutor de seus parceiros.

Este patrimônio é tanto mais precioso porque os valores que o constituem decorrem do espírito de moderação que caracteriza a diplomacia brasileira. O relacionamento harmonioso com os países vizinhos, o recurso ao diálogo e à cooperação, a defesa permanente da paz e do desarmamento e o respeito ao Direito Internacional são todos fatores da imagem de um país que se faz respeitar no cenário internacional e de uma diplomacia que inspira confiança e credibilidade. Como um dos responsáveis pela construção e preservação deste legado de respeitabilidade, cabe ao Itamaraty atuar não apenas com vistas a objetivos imediatos, mas também - e sobretudo - de olhos postos no futuro, ou seja, em obediência ao imperativo de manter a coerência de nossa atuação diplomática.

A observância de princípios e valores não significa, no entanto, que a ação externa deva degenerar em dogmatismo ou principismo extremado. É necessário dispor de pragmatismo e flexibilidade no tratamento das questões internacionais, quando menos pelo caráter mutável da agenda internacional, das configurações de poder entre os países e do próprio estágio de desenvolvimento do País. Por vezes, a mudança tópica é condição para o respeito a objetivos mais gerais e permanentes. O exercício da flexibilidade e do pragmatismo não pode, entretanto, implicar o abandono de valores invioláveis, que constituem a própria identidade da atuação diplomática do Brasil. Na verdade, o respeito a princípios que nos são caros e o recurso ao pragmatismo moderado devem complementar-se no propósito maior de assegurar os interesses nacionais.

\section{O relacionamento do Itamaraty com a Sociedade}

Inspirado por estes objetivos permanentes, o Itamaraty desempenha duas tarefas primordiais que antecedem a execução da política externa: a formulação de suas diretrizes gerais e a coordenação com os demais órgãos do Governo e entidades civis.

O processo de formulação da política externa compreende, de um lado, a interpretação e avaliação da realidade internacional e, de outro, a identificação do 
interesse nacional, em cada uma das situações apresentadas, a partir das necessidades domésticas e dos constrangimentos externos. O Itamaraty atua com base no pressuposto de que a política externa brasileira não pode ser meramente reativa ante os acontecimentos e tendências das relações internacionais. A ação externa não deve ser uma simples sucessão de respostas caso a caso, sem um mínimo de coerência e articulação de objetivos, meios e princípios. Ao contrário, cabe ao Ministério cotejar interesses domésticos e a realidade internacional, para formular diretrizes gerais de atuação que irão permear as escolhas e decisões em cada um dos itens da agenda diplomática. Fundada nestas diretrizes, a política externa ganha sentido e torna-se instrumento para os objetivos mais amplos do Governo e da sociedade.

A tarefa de coordenação da política externa compreende, de um lado, o trabalho de informação da sociedade sobre a realidade internacional e, de outro, a tarefa de harmonizar posições entre os grupos sociais e as diversas instâncias governamentais sobre temas da pauta diplomática. Sob a liderança do Presidente da República, devem combinar-se o intercâmbio de pontos de vista entre Governo e sociedade e a coordenação de posições entre Ministérios e entre os Poderes Executivo, Legislativo e Judiciário.

A importância do trabalho de coordenação deve-se à grande multiplicidade e complexidade dos temas da política externa. A multiplicidade de temas exige do diplomata transitar por áreas tão distintas quanto meio ambiente, desarmamento, direitos humanos, comércio exterior, ciência e tecnologia, transportes, comunicações e narcotráfico. Não basta, no entanto, que o agente diplomático conheça de modo profundo a realidade nacional e tenha uma formação ampla capaz de habilitá-lo a negociar temas de natureza variada. A complexidade de cada um dos assuntos exige a articulação do Itamaraty com os demais Ministérios e órgãos do Governo, a fim de que o trabalho diplomático reflita o tratamento preciso e abalizado dos temas, mantendo a necessária coerência com as posições e políticas que o Governo brasileiro adota no plano doméstico.

Ao longo dos últimos quatro anos, o Itamaraty buscou permanentemente aperfeiçoar o relacionamento com outros setores do Governo. Um exemplo é o das negociações com vistas à formação da área de Livre Comércio das Américas (ALCA). A variedade dos temas envolvidos e sua importância para diversos setores da economia levou o Itamaraty não apenas a intensificar o diálogo com outras unidades governamentais, mas também a institucionalizá-lo. Criou-se a Seção Nacional da ALCA (SENALCA), composta por representantes de 12 ministérios e 5 órgãos públicos, além de representantes do Congresso e de entidades civis, que se reúnem regularmente para traçar estratégias para as negociações e avaliar seus resultados.

O MRE mantém coordenação constante com uma série de órgãos estatais e coopera com interlocutores diversos, tanto em nível federal como estadual e 
municipal. A rede de contatos do Itamaraty é das mais extensas da administração pública, pois a área de atuação dos diferentes órgãos possui muito freqüentemente uma dimensão externa, que tende, no contexto da globalização, a aprofundar-se e que exige da chancelaria contribuições contínuas.

Uma das vertentes de crescente importância de nossa relações internacionais é a dos interesses externos de estados e municípios. Em quadro de valorização dos investimentos diretos de empresas transnacionais e de aumento do peso do comércio exterior na economia, os governos estaduais e municipais passaram a desenvolver contatos internacionais mais freqüentes e a demandar maior apoio do MRE. Para fazer frente a esta necessidade, o Itamaraty criou em 1997 uma unidade, a Assessoria de Relações Federativas, voltada exclusivamente para o relacionamento com estados e municípios. O objetivo, que vem sendo plenamente alcançado nestes dois primeiros anos de funcionamento, é aprimorar o diálogo com as unidades da Federação a fim de que seus interesses de âmbito internacional sejam melhor atendidos, em perfeita consonância com a política externa do País.

Cumpre também ao Itamaraty a função de informar o Congresso a respeito dos temas da agenda internacional. Cabe ao Legislativo acompanhar a execução da política externa e, por vezes, aprovar alguns de seus atos específicos; é o caso, por exemplo, da ratificação de acordos celebrados pelo Brasil. Por outro lado, várias normas internas repercutem no relacionamento externo do País. Isto cria para o Itamaraty a tarefa de subsidiar constantemente o trabalho da Câmara e Senado, enquadrando discussões tópicas no contexto de nossa inserção internacional. Fora este apoio a atividades permanentes do Congresso, é preciso responder também a solicitações pontuais, feitas por parlamentares com base em comunicações recebidas de eleitores, associações profissionais e outros núcleos de organização comunitária. A meta do MRE é a de garantir transparência em seu diálogo com a sociedade, o que torna o relacionamento com os representantes legítimos da população um fator de capital importância.

O aprimoramento do diálogo com a sociedade é indispensável por três razões fundamentais. Duas são evidentes: a necessidade de que a política externa reflita cada vez mais fielmente os interesses da população e de que o Itamaraty preste conta com regularidade de suas políticas e ações. A terceira razão é menos óbvia, mas de fundamental importância: é o respaldo da sociedade que legitima e fortalece as posições de negociação brasileiras nos mais diversos temas internacionais. O apoio das entidades civis, da Imprensa e da população em geral às orientações da atuação externa é um asset diplomático. A preservação dos interesses do País no relacionamento com os demais Estados será tanto mais defensável quanto mais respaldadas internamente forem as posições adotadas pelo Itamaraty.

Cito uma vez mais o exemplo das negociações da ALCA. Tendo em vista a importância do estabelecimento de uma área de livre comércio hemisférica e 
seus futuros efeitos sobre a sociedade como um todo, o Itamaraty buscou ao máximo estimular a reflexão e o debate sobre o assunto, por meio dos contatos com a imprensa e com entidades de classe, tanto empresariais quanto sindicais. O resultado foi o adequado amadurecimento da visão brasileira sobre a iniciativa comercial e o fortalecimento da capacidade negociadora do País em todas as reuniões, especialmente durante o período da Presidência Pró-Tempore brasileira, culminado com a Reunião Ministerial de Belo Horizonte, em maio de 1997. O sucesso na defesa da visão brasileira e do MERCOSUL quanto à constituição de uma área de livre comércio nas Américas deveu-se em grande medida à mobilização da sociedade e à maior legitimidade das posições defendidas ante os demais países.

Há muitos outros exemplos de esforços realizados pelo Itamaraty no sentido de aproximar mais a sociedade das discussões sobre temas importantes da nossa agenda externa. Cito apenas a criação, em 1995, do Foro Consultivo EconômicoSocial do MERCOSUL, que reúne representantes sindicais, empresariais e de órgãos de defesa do consumidor dos quatro países. A iniciativa veio reafirmar o propósito de que, sem a participação dos mais diversos segmentos sociais, o processo de integração perderá legitimidade e força. O MERCOSUL foi criado e avança inspirado na convicção de que a integração como instrumento para o desenvolvimento e a cooperação regional somente terá sucesso se contar com a vigilância e o apoio de toda a sociedade.

A execução da política externa pelo Itamaraty obedece ainda a dois cuidados básicos: o acesso à informação e a exigência do registro histórico.

Em consonância com o regime democrático e com o imperativo de prestação de contas à sociedade, o Ministério procura oferecer amplo acesso à informação. É nossa preocupação atuarmos da forma mais transparente possível. A chamada "diplomacia secreta”, de decisões de gabinetes e de restrições à circulação de informações só se justifica em algumas situações extremas, em que a segurança do Estado ou o andamento das negociações com outros países exigem o tratamento sigiloso. À exceção destes casos, a sociedade deve ser permanentemente informada não apenas porque o Governo deve prestar conta de seus atos, mas também para que a sociedade possa ser melhor ouvida.

Um exemplo da necessidade de melhor informar o público sobre as ações da política externa foram as discussões sobre os benefícios das viagens presidenciais ao exterior. Um tratamento simplificado por parte da imprensa deixou a falsa impressão de que as visitas realizadas pelo Senhor Presidente da República rendiam escassos ganhos para o País. Uma das razões para esta interpretação era justamente o fato de que se noticiava apenas a viagem em si, em seus aspectos protocolares, não a evolução do relacionamento entre o Brasil e o país visitado a partir de então. Os fluxos de investimento, a criação de empreendimentos conjuntos, o intercâmbio científico e tecnológico, o comportamento da balança comercial e a afinidade de posições em foros internacionais são aspectos que podem ser influenciados por 
gestos políticos de aproximação como as visitas de alto nível. Por serem menos ponderáveis e despertarem menor atenção, estes dados acabam, no entanto, por não serem transmitidos à sociedade, o que exige do Itamaraty um esforço adicional de divulgação e informação do público. Por esta razão, temos intensificado os contatos com a imprensa e a sociedade civil de maneira geral.

Outro cuidado do Ministério das Relações Exteriores na condução da política externa é a exigência do registro histórico: todas as decisões de política externa devem ser registradas, o que justifica o empenho do Itamaraty tanto na preservação de um processo de decisão fundamentado na circulação de expedientes quanto na manutenção dos arquivos históricos. O compromisso da chancelaria estabelecese, portanto, com as gerações presentes e futuras, seja pelo acesso às últimas informações sobre a política externa, seja pela preservação da memória de nossa diplomacia.

\section{Mudanças institucionais e prestação de serviços}

Como instrumento primordial da execução da política externa, o desempenho da atividade diplomática desdobra-se em três funções básicas, classicamente associadas ao trabalho dos diplomatas na condição de representantes de seu Governo no exterior: a representação, a negociação e a informação.

Além destas funções clássicas, o Ministério das Relações Exteriores atua também por meio da prestação de serviços específicos, de que se beneficiam tanto o poder público quanto indivíduos, associações e empresas. Neste segundo campo, realiza-se uma filtragem das solicitações feitas; identificam-se interesses particulares que vão ao encontro dos objetivos nacionais e contribuem para que sejam alcançados. Essa revisão crítica de demandas - cujo número tem aumentado rapidamente com a expansão da agenda internacional e o aprofundamento do processo de inserção internacional do Brasil - permite evitar qualquer tendência de "privatização" da atuação do Itamaraty.

Dentre os serviços prestados ao público em geral, destacarei três das áreas em que o Itamaraty procurou empreender nos últimos quatro anos uma reformulação dos seus métodos de trabalho e relacionamento com o público: a assistência aos brasileiros no exterior, a promoção comercial e a difusão cultural. Mencionarei de início a assistência a brasileiros no exterior, tarefa tradicional da diplomacia que o Itamaraty assumiu como prioritária, em cumprimento de orientações estabelecidas pelo Presidente Fernando Henrique Cardoso.

Como instrumento dos interesses nacionais, a política externa acompanha necessariamente a evolução da sociedade. O Brasil revela, em tempos recentes, uma inversão da direção tradicional de seus fluxos populacionais: a vinda de imigrantes, que cristalizou uma nacionalidade pluralista e harmônica, paulatinamente abriu espaço para um movimento significativo de brasileiros que seguem para o exterior. 
Hoje, já nos aproximamos de um total de 2 milhões de brasileiros que vivem fora do País, sobretudo nos Estados Unidos, América do Sul, Japão e Europa Ocidental. A saída desses nacionais, freqüentemente provocada pela crise econômica que só recentemente logrou-se controlar, não implica ruptura com o País. Pelo contrário, as manifestações constantemente recebidas por nossa rede consular e o volume de recursos que são anualmente remetidos por brasileiros no exterior - estimados em aproximadamente 3 bilhões de dólares anuais - comprovam a permanência de profundos vínculos com a pátria e do desejo de retornar.

Ao número de nacionais emigrados, devemos acrescentar os 3 milhões de turistas brasileiros que anualmente viajam ao exterior, graças às condições favoráveis hoje existentes. Configura-se, desse modo, o contingente expressivo de potenciais usuários de nossos serviços consulares, que englobam, entre outros, atos notariais, assistência e defesa de direitos. É importante notar o sentido político deste apoio: a atuação do consulado traduz o interesse do Estado por seus nacionais afastados e sua determinação de protegê-los. Representa, por isto, um fator de preservação da cidadania, cujas exigências formais, no tocante ao cumprimento de obrigações referentes ao serviço militar, justiça eleitoral e receita federal, são atendidas por intermédio da repartição consular.

Buscando responder ao desafio assim constituído, o Itamaraty reforçou sua estrutura em Brasília - por meio da criação da Diretoria-Geral Consular, Jurídica e de Assistência a Brasileiros no Exterior e do Núcleo de Assistência a Brasileiros - e no exterior, com a abertura de novos Consulados-Gerais. Outra importante inovação foi a implementação de missões consulares itinerantes, que levam serviços e apoio a nacionais que enfrentam dificuldades para deslocar-se até a repartição consular mais próxima.

Estabeleceram-se também os Conselhos de Cidadãos, foros de discussão informais e apolíticos que reúnem autoridades consulares e representantes das comunidades de brasileiros no exterior. Essas unidades, que vêm se constituindo nos Estados Unidos, Japão e Europa, comprovam o interesse do Itamaraty em trabalhar junto com a sociedade, ouvindo seus problemas e suas críticas e debatendo possíveis soluções e iniciativas.

Na área de promoção comercial, o MRE atua por meio do estímulo às exportações brasileiras de bens e serviços, identificando oportunidades de investimentos, disseminando informações sobre oportunidades existentes em mercados internacionais e contribuindo para a transferência de tecnologia. Com isto, promove-se uma participação brasileira mais intensa na dinâmica econômica internacional, fator de crescente relevância para o desenvolvimento do País.

$\mathrm{O}$ apoio oferecido destina-se sobretudo às pequenas e médias empresas cuja capacidade de captação de informação é, naturalmente, menor - o que não implica em absoluto exclusão de grupos maiores. Neste contexto, o Itamaraty tem trabalhado em estreita coordenação com entidades como o SEBRAE, o que permite 
acesso a ampla rede de potenciais beneficiários. Assinamos ainda diversos convênios com vistas ao adensamento do sistema de promoção nas regiões Norte e Nordeste, sobretudo para o aproveitamento das perspectivas criadas pelo Mercosul.

Dentre os instrumentos específicos de promoção criados pelo Itamaraty, destacaria, de início, o SIPRI - Sistema de Promoção de Investimentos e Transferência de Tecnologia para Empresas - que articula Setores de Promoção Comercial das Missões brasileiras no exterior e "pontos focais”, dos quais já existem vinte e sete distribuídos por todo o País. Cabe ao SIPRI divulgar no Brasil e no exterior oportunidades capazes de propiciar aporte de capitais e tecnologia para empresas nacionais.

Outro importante instrumento é o Centro de Promoção da Eficiência Comercial-CPEC - que tem por objetivo estimular a competitividade das empresas nacionais. O CPEC tem como uma de suas principais funções o apoio à criação, desenvolvimento e operação de "trade points", centros facilitadores de comércio que reúnem os diversos participantes de operações internacionais, tais como alfândega, câmara de comércio, transportadoras e companhias de seguro, entre outros. Oito "trade points" já existem no Brasil, conectados a uma rede de aproximadamente oitenta no mundo.

Além da criação destes instrumentos, o Itamaraty implementou nos últimos dois anos um novo modelo de gestão da promoção comercial, fundamentado em análise realizada por empresas de consultoria. Como resultado das avaliações feitas, reestruturou-se a rede de escritórios comerciais no exterior e criou-se a chamada "Brazil Trade Net", um sistema de informação e inteligência comercial que atende mais rápida e eficientemente às demandas dos exportadores brasileiros.

Outro serviço oferecido pelo Itamaraty ao público que cabe destacar é a atividade de divulgação cultural. No cenário internacional contemporâneo, a capacidade de uma nação para ocupar espaços políticos relevantes e beneficiarse de oportunidades econômicas dependerá fortemente de sua habilidade em transmitir uma imagem positiva.

Tornar-se conhecido no mundo é da maior importância, o que não implica mascarar a realidade nacional. O compromisso com a democracia e a transparência exige igual franqueza no trato, ante as demais nações, dos desafios que o Brasil enfrenta. O MRE, entretanto, procura dar conhecimento das ações implementadas por governo e sociedade com o objetivo de combater tais problemas. É necessário desfazer imagens estereotipadas por meio da apresentação de informações sobre aspectos menos conhecidos de nosso País. Nossa cultura, com sua riqueza característica, representa, neste contexto, importante caminho para a redefinição de visões simplificadas do Brasil.

Deve ser notado, entretanto, que ao lado desse sentido político da diplomacia cultural, que revela sua capacidade de atender a interesses do Estado, existe um serviço que é oferecido aos produtores culturais brasileiros. Por meio do Itamaraty, 
vários artistas puderam ter acesso ao público internacional, consolidando, com isto, carreiras que de outro modo poderiam permanecer restritas ao espaço cultural brasileiro. Este processo mutuamente benéfico tem como exemplo clássico o papel do MRE na divulgação da "bossa nova” nos Estados Unidos. Estabeleceu-se uma referência marcante da nacionalidade brasileira no mundo e abriu-se espaço para obras que, por sua qualidade intrínseca, rapidamente tornaram-se autônomas frente a qualquer apoio oficial. Novamente são associados interesses específicos e os objetivos gerais que orientam permanentemente a atividade diplomática.

Caberia acrescentar, finalmente, que, ao ajudar a canalizar a oferta cultural internacional para o País, o Itamaraty beneficia também o público brasileiro. A organização das Bienais Internacionais de São Paulo, por exemplo, tem contado com o auxílio de nossa rede de Embaixadas e Consulados, cuja proximidade com os vários ambientes artísticos do mundo permite identificar e contatar produtores e divulgadores estrangeiros capazes de contribuir para o êxito do evento.

Tanto nas atividades diplomáticas tradicionais quanto na prestação de serviços, o Itamaraty orientou-se no anos de 1995 a 1998 por uma meta fundamental, o da crescente aproximação da instituição com a sociedade. Embora desde a redemocratização do País em 1985 o MRE já se viesse abrindo, de modo progressivo, ao diálogo com os mais diversos grupos e entidades sociais, operou-se ao longo dos últimos quatro anos um aprofundamento da interação com parlamentares, governos estaduais e municipais, empresários, sindicalistas, ONGs e imprensa. Esta nova dimensão do diálogo com a sociedade derivou do espírito democrático e de transparência que marca o Governo do Presidente Fernando Henrique Cardoso e da convicção de que a política externa será tanto mais eficiente como instrumento para o desenvolvimento do País quanto mais afinada estiver com os anseios e preocupações da sociedade brasileira.

Novembro 1998

\section{Resumo}

Artigo de natureza institucional sobre execução da política exterior no primeiro Governo Fernando Henrique Cardoso. Essa política externa, cujos princípios de atuação são claramente definidos, foi marcada por um permanente esforço de intensificar o diálogo com outros setores do Governo e entidades civis (iniciativa privada, organizações sociais e a população em geral) e de aumentar a transparência do processo de decisão. O Itamaraty buscou modernizar-se para fazer frente aos desafios da sociedade globalizada e democratizada, cujo interesse por temas de política externa é crescente. Tais transformações se guiaram pela convicção de 
que a instituição precisa aperfeiçoar os serviços que presta à sociedade, por meio de ações que favoreçam mais diretamente os cidadãos brasileiros tanto no Brasil quanto no exterior.

\section{Abstract}

The article deals with the institutional framework supporting the implementation of Fernando Henrique Cardoso's foreign policy. This policy, whose principles are well defined, has emphasized a continuing dialogue with other areas of the Government and with civil entities (business sector, social organizations and people in general), as well as an improvement in the transparency of the decision making process. The Foreign Affairs Ministry (Itamaraty) engaged itself in a modernization path in order to face the challenges of a new, globalized and democratized, society, whose interest in foreign policy issues is growing. These changes are oriented by the conviction that the institution has to improve its services to society, taking concrete actions to help Brazilian citizens in the country and abroad.

Palavras-chave: Brasil. Política externa. Ministério das Relações Exteriores. Key-words: Brazil. Foreign policy. Ministry of Foreign Affairs. 